\title{
Shaping EFL Teachers' Critical Intercultural Awareness through Intercultural Education
}

\author{
Andi Susilo ${ }^{1}$, Ping Yang ${ }^{2}$, Ruying $\mathrm{Qi}^{3}$ \\ $\{18811399 @$ student.westernsydney.edu.au'1,P.Yang@westernsydney.edu.au², \\ R.Qi@westernsydney.edu.au $\left.{ }^{3}\right\}$
}

Western Sydney University, Australia

\begin{abstract}
English as a foreign language (EFL) programs necessarily address intercultural communication competence (ICC). As part of their learning outcomes, they seek to equip students with knowledge, attitudes, and communication skills to help them engage effectively in diverse sociocultural contexts. However, lack of critical intercultural awareness (CIA) is a key factor that hinders EFL teachers from promoting students' ICC. This article focuses on strategies to develop EFL teachers' CIA in the Indonesian higher education context by conceptually examining the in-progress formation of EFL teachers' CIA from two perspectives. First, how teaching intercultural education encourages EFL teachers' awareness and understandings of their own culture and worldview frameworks. Second, how developing syllabus documents on intercultural aspects and selecting interculturally appropriate learner-centred resources and pedagogical tasks can proactively promote ICC. Furthermore, the paper presents a sample activity to promote intercultural learning that can foster EFL teachers' CIA.
\end{abstract}

Keywords: critical intercultural awareness, intercultural communication competence, intercultural communicative language teaching, higher education

\section{Introduction}

Intercultural communication competence (ICC) has gained much attention from scholars and researchers. In an English as lingua franca perspective, ICC is framed as a sociocultural process which is situated in both Anglophone and non-Anglophone contexts. In these contexts, the acquisition of linguistic and general knowledge of diverse cultures is more desirable than linguistic and general knowledge of any target language [1]. Similarly, in EFL contexts, ICC is identified as the ability to understand and interact with people (either from the same or different regions/countries) who have varied values, beliefs, and behaviours using linguistically appropriate and culturally acceptable language to enhance connections [2]. An implication is that English language teaching (ELT) should equip learners with communication skills as well as help them acquire intercultural knowledge, skills, and attitudes to assist them to communicate effectively in global contexts [3].

As key stakeholders, EFL teachers play a pivotal role in promoting students' ICC through culturally appropriate teaching platforms. The acquisition of such competence will help EFL teachers and students build mutual understanding, encourage acceptance of different perspectives and maintain effective interaction with other language users [4]. Addressing intercultural education will enable EFL teachers to equip students with strong ICC, and this can encourage them to enhance their performance in various classroom activities and achieve greater results in learning [5]. Thus, EFL teachers need to develop their syllabus documents and classroom instructions to explicitly address ICC as one of learning aims to aid graduates become competent intercultural speakers and enable them to engage effectively in the globalised world [6].

Although ICC is perceived as a predetermining factor which leads to successful EFL learning, it receives relatively little emphasis in syllabus and classroom practices [5, 7]. The lack of intercultural awareness among EFL teachers themselves is one of the key issues [8]. Another issue is that most EFL teachers may not receive any formal training in intercultural teaching, thus being unprepared for the task [9]. Other challenges in teaching ICC include the complexity of cultural factors, limited learning resources, and little support from institutions or policymakers $[7,10]$. These factors help explain why intercultural learning is mostly absent in Indonesian higher education contexts. 
To establish effective communication across linguistic and cultural boundaries, EFL teachers need to consider developing their critical intercultural awareness (CIA) as an essential element of ICC [4]. Having strong CIA will encourage EFL teachers to improve intercultural knowledge, skills, and attitudes; coincidently, these can foster intercultural learning in the classroom. Significantly, Indonesia's multilingual and multicultural context works to unconsciously co-construct EFL teachers' CIA. For instance, they work with heterogenous students and colleagues from different socio-cultural backgrounds and undertake collaborative research or community services with the local and international counterparts. The development of CIA can also be shaped through conscious processes, i.e., being involved in professional development programs or associations in domestic or international forums [11, 12], attending intercultural trainings [13], or undertaking intercultural education in the classroom [11]. This last strategy has twofold benefits which are the focus of this paper. Firstly, promoting intercultural learning provides opportunities for teachers to develop their intercultural awareness and enables them to facilitate effective learning in the given context. Secondly, it models to students and helps promotes their ICC to help them continue to engage in global learning after they graduate from the university [9].

This article conceptually examines the ongoing formation of EFL teachers' CIA. It first presents the theoretical frameworks to operationally define the related literature of intercultural communication competence, intercultural communicative language teaching, and intercultural awareness. It then discusses the dynamic process of CIA development embedded in EFL teachers' teaching abilities, such as foundational competence, syllabus design, and facilitation skill. To provide insights into these processes, a sample activity to promote intercultural learning and foster CIA is proposed prior to the conclusion.

\section{Theoretical framework}

The current literature helps to better understand the underlying concept of intercultural awareness including intercultural communication competence and intercultural communicative language teaching.

\subsection{Intercultural communication competence}

In today's globalised world, people from different cultures and nationalities are living and interacting with one another in real-life situations and via social media. This suggests individuals need to increasingly become aware of and competent in using linguistically appropriate and culturally acceptable language. Given this, developing ICC is important.

The concept of ICC is rooted in Hymes's work on communicative competence (CC) [14]. The notion of $\mathrm{CC}$ signifies the acquisition of the proper form and function of language that is linguistically correct, appropriate for the context and culture of the target language being learned. Communicative competence thus plays an important role in multilingual interactions as it assists individuals to communicate with other speakers across countries and cultural boundaries. Thus, from CC, the concept of ICC emerged to become broadly recognised as the basic competence to effectively communicate with diverse people and engage in global communication [15].

Scholars in the area of intercultural studies conceptualise ICC in various ways. Byram [15] uses the term of intercultural communicative competence to refer to qualified intercultural speakers. Accordingly, ICC entails linguistic competence, sociolinguistic competence, discourse competence, and intercultural elements. Wiseman uses the term of intercultural communication competence to signify intercultural knowledge, motivation, and skills [16]. Both terminologies emphasise language users' abilities to communicate with other people from different cultural and linguistic backgrounds and engage in intercultural encounters. While these two scholars mainly focus on the verbal dimension of interculturality, Yang [11] in his work on TESOL teachers' intercultural identity, extends the concept of ICC to include non-verbal communication competence component and its multiple dimensions such as paralinguistics, kinesics, proxemics, and other related non-verbal attributes.

In this article, we use the term intercultural communication competence (ICC) to define and acknowledge the importance of both verbal and non-verbal aspects of interculturality. Grounded in Byram's ICC model [15], ICC is the ability to communicate, behave, and interact effectively with people from different countries, regions or group communities who are diverse in culture, believes, and perspectives to exchange information, establish connection, and maintain relationships. This notion suggests developing ICC helps learners reach their potential competence as intercultural speakers and use their language to successfully "negotiate a mode of communication and interaction, or act as a mediator between people of different cultural 
origins" [15]. Accordingly, ICC entails understandings about social groups, cultural beliefs, practices, products, and interactional features; curiosity, willingness, openness, respect, and readiness to suspend disbelief about other cultures and about one's own. It also encompasses communication skills in interpreting and relating, and skills of discovery and interaction - the former deals with the abilities to make a sense of other cultural perspectives and connect over both similarities and differences, while the latter concerns the capabilities to acquire new cultural knowledge/perspectives, practices, or products, and make use of them in authentic communication and interactions [15]. Thus, ICC demonstrates the capacity to critically evaluate cultural perspectives, practices, and products in the lens of one's own and other cultures. All of these principles emerge in the underlying framework of intercultural education.

\subsection{Intercultural communicative language teaching}

The intertwined nature of language and culture has long been acknowledged in EFL classrooms where teachers need to integrate cultural aspects of the English learning resources and context. This is based on the seminal pedagogical understanding that genuine communication mainly takes place and is embedded in the contexts of culture (i.e., values, beliefs, religious or social practices, etc.), or situation (i.e., daily conversation, formal/informal chats, public speech, etc.), and that these two contexts shape the actual use of English for a variety of communicative purposes [17]. This notion informs the underlying theory of the communicative language teaching (CLT) approach which has long been applied by teachers. CLT emphasises the development of students' communicative competence as the primary goal of English as a second or foreign language learning [18].

In a globally interconnected world, where communication across cultural and linguistic borders happens more frequently than ever before, the differing roles of English and ELT in classrooms are becoming more defined. Scholars in pedagogical areas such as English as an international language (EIL), English as additional language (EAL) and English as lingua franca (ELF) advocate that the goal of ELT programs should not require students to achieve native-like linguistic and socio-cultural competence [19-21]. This critical view is based on the fact that the majority of English as second/foreign language (ESL/EFL) users and learners come from non-Anglophone countries (e.g., China, India, Indonesia, Saudi Arabia) [19] where English is largely taught for pedagogical purposes; English thus serves as the medium of intercultural communication among users from diverse socio-cultural and linguistic backgrounds. Given this fact, ELT programs necessarily put emphasis on achieving ICC as a key goal of English learning so that students can learn to communicate effectively across linguistic and cultural boundaries and engage in global learning. Intercultural education, or so-called intercultural communicative language teaching (iCLT), is a promising interculturallyrelated teaching platform to integrate language and culture in diverse cultural and linguistic learning settings [22].

Drawn from Byram's comprehensive model of ICC [15], teachers who intend to implement an intercultural education model in the classroom need to consider the integrated elements of communicative competence and intercultural competence. Accordingly, intercultural education entails linguistic, sociolinguistic, discourse, and intercultural components. The linguistic aspect deals with the acquisition of linguistic codes covering grammatical rules, vocabulary, phonology, and graphology; the sociolinguistic dimension relates to the mastery of socio-cultural codes including appropriate use of linguistic codes, register, politeness, and style in a given situation; and the discourse aspect concerns the ability to select, sequence, and arrange language structures into different types of cohesive and coherent expressions or written texts [23]. Additionally, intercultural components embrace the acquisition of knowledge, skills, and attitudes as well as critical awareness as necessary elements of ICC [15].

The implementation of iCLT has received widespread support from researchers and classroom practitioners. For example, Tran and Duong [24] undertook a study to examine the effectiveness of iCLT in a Vietnamese EFL context and found that a 13-week course using this approach improved students' language proficiency and intercultural competence. Having observed the implementation of iCLT in English-dominant multicultural classrooms in New Zealand, Ramirez [22] investigated teachers' perspective and practices of iCLT by examining six principles: (a) integrating language and culture from the beginning, (b) engaging learners in genuine social interaction, (c) encouraging and developing an exploratory and reflective approach to culture and culture-in-language, (d) fostering explicit comparisons and connections between languages and cultures, (e) acknowledging and responding appropriately to diverse learners and learning contexts, and (f) emphasising intercultural communicative competence rather than native-speaker competence [22]. The study reported that most iCLT principles were understood and carried out by teachers in the classroom and beyond it although some challenges were identified in fully implementing all six principles. 
For iCLT to be successfully undertaken, EFL teachers need to have adequate intercultural teaching abilities. Dimitrov and Haque [9] provide guidelines for teachers to reflect on their competency in teaching across linguistic and cultural settings which embraces three interrelated skills as follows.

a. Foundational competencies: focus on instructor self-awareness and the ability to model intercultural competence for students.

b. Facilitation skills: build on the foundational competencies, allowing instructors to interact with students and encourage interaction among students in ways that are respectful of diversity.

c. Curriculum design competencies: reflect the skills of instructors who not only respond to diversity in their classroom, but also intentionally engage students in global and intercultural learning activities or discussions of social justice issues in order to promote global learning outcomes.

\section{Shaping EFL teachers' critical intercultural awareness}

\subsection{From cultural awareness to intercultural awareness}

Intercultural awareness (IA) is widely acknowledged as an important social element of the $21^{\text {st }}$ century which potentially fosters a willingness to communicate with people from diverse linguistic and cultural backgrounds to increase mutual understanding. From the perspective of ELF, IA is the extension of cultural conceptions from cross-cultural perspectives with an emphasis on understanding of the national and the target culture to intercultural and translingual frameworks [25]. Baker conceptualises IA as "a conscious understanding of culturally based forms, practices, and frames of references" and the capacity to make use of these conceptions in intercultural encounters in flexible and culturally appropriate ways [1]. Based on this conception, the acquisition of IA is evident from two standpoints: conceptual and practice-oriented. The former deals with the acquisition of attitude towards and knowledge of culture, and the latter focuses on skills and behavioural aspects to successfully engage in intercultural communication.

Another concept proposed by Byram is that critical cultural awareness/political education refers to the ability to "evaluate critically and on the basis of explicit criteria, perspectives, practices, and products in one's own and other cultures and countries" [15]. He proposes that intercultural awareness entails the abilities to:

1. identify and interpret socio-cultural values depicted from learning materials (i.e., video-clips) in one's own and other cultures in a non-judgemental way;

2. critically analyse the events or documents in accordance with explicit perspectives and criteria;

3. interact and mediate in intercultural exchanges referring to explicit criteria.

This article uses critical intercultural awareness (CIA) and discusses the in-progress formation of Indonesian EFL teachers' CIA when they undertake intercultural education in their classrooms. Developing CIA enables them to achieve two key goals: on-going development of ICC and interculturality-based teaching practices.

\subsection{Co-Construction of EFL teacher CIA: A dynamic process beyond classroom instructions}

Indonesian EFL teachers are assigned tasks to help assist graduates to have the standardised and specialised skills related to their discipline as well as strongly attain attitudes. The conception of attitudes is informed by the Ministerial regulation on national standard of higher education [26] that all graduates should have affective competencies, such as valuing a variety of cultures, thoughts, religions, faith, ideas, and intellectual property rights, collaboration with others, as well as social sensitivity and compassion for the society and environment. To help students achieve the desired outcomes, EFL teachers should ensure that inclusive education is well-addressed in their classrooms via students' demonstrating respect for otherness, i.e., language proficiency, ethnicity, race, gender, national origin and other unique differences [27]. They necessarily need to nurture diversity in the classroom through interculturally appropriate teaching platforms to assist students in communicating and engaging effectively in diverse cultural contexts [9]. Addressing intercultural education potentially benefits EFL teachers themselves from developing their CIA.

The ongoing development of teacher CIA can be viewed from two key perspectives: co-construction of interculturality and interculturality-oriented curriculum development First, intercultural education enables EFL teachers to extend their awareness and understanding of their own culture and worldview frameworks. Their perceptual lenses of interculturality and intercultural teaching are co-constructed when they interact with students discussing various topics on global or socio-cultural issues. Such experiences shape their own 
and other cultural identities [9] and promote their awareness and openness to the variety of students' ideas, assumptions, and ways of learning. Having such views of diversity allows them to critically identify and analyse any possible factors that can influence classroom dynamics. This insight helps them become effective intercultural facilitators that allow classroom members to engage actively in intercultural learning so that they can gain mutual understanding and support the learning of others. Moreover, the subsequent process of intercultural teaching may improve EFL teachers' perceived awareness and abilities to model to students a variety of communication styles across cultural settings. They would be better able to encourage perspectivetaking in the classroom, openness to receive critique, and non-judgemental ways of thinking [9].

Second, building on the co-constructed interculturality, EFL teachers are likely to be more reflective and inclusive in designing curricula and facilitating student learning [9]. The ongoing progress of EFL teachers' awareness will be likely to transform into actions when they develop curriculum documents by including intercultural features, selecting interculturally appropriate learning resources and pedagogical tasks, and applying authentic assessments which empower them to demonstrate their ICC. Thus, it is likely that EFL teachers would be more aware of and reflective on the approaches of their teaching practices to equip students with skills necessary to communicate and engage effectively in today's global society. Moreover, EFL teachers' CIA is manifested to classroom instructions when they scaffold in-class discussions and meet the learning needs of students of varied cultural backgrounds. Intercultural education encourages them to transform intercultural modalities into actions to ensure that the learning practices are learner-centred, that multi-ideological perspectives are negotiated, and that pair/group discussion of heterogonous class members are well-facilitated in or beyond the classrooms. They are likely to equip students with a variety of communication styles in diverse cultural settings, and expose and provide various feedback styles across cultures that fit their needs [28].

\section{Promoting intercultural learning: the use of video clip-assisted intercultural learning tasks}

The use of video-clips as EFL teaching and learning materials has long been acknowledged to assist with learners' development of language skills [29]. Some scholars further confirm the use of video clips can enhance learners' cultural knowledge of practices or products [30,31]. Video clips thereby offer opportunities to promote and facilitate intercultural learning in foreign language classrooms [32] owing to their rich sources of audio and visual information, particularly about diverse societies and cultures. Digital technology may accelerate intercultural learning since it provides updated technologies that teachers can use in their instruction. Huge numbers of easily accessible digital video files are available online - most via popular video repositories such as YouTube.com and Ted.com. Such sites open up opportunities for teachers to search for appropriate resources to help meet and extend learners' needs in intercultural learning through films, talks, or conversations about socio-cultural realities.

Video clips serve as potential learning materials to promote students' awareness of socio-cultural realities embedded in the selected clips. Some studies reveal the effective use of intercultural film clips help to build learners' intercultural awareness as they address ideas and concepts of intercultural encounters and contain stories that reflect cultural differences [33-36]. Several classroom reports emphasize the importance of incorporating cultural-related video clips in intercultural learning. For example, the use of YouTube videos as realia could stimulate cultural lessons and enhance exposure to English variations from across the world [37]. Likewise, television documentary series taken from YouTube such as "An Idiot Abroad" can promote "cultural values, ethnocentrism, and intercultural communication competence" [38]. Accordingly, video clips can motivate learners and prompt thoughtful discussions on communication in diverse communities. However, EFL teachers need to critically consider the appropriateness of video content, the length, and ways to most effectively present and utilize the clips.

The use of video clips as culturally appropriate learning resources cannot work alone or in isolation to promote learners' critical intercultural awareness [39]. They mainly serve as learning resources and should be integrated along with other interculturally appropriate learning tasks. In this vein, the tasks function as activities which can assist learners to "communicate or make meanings of sociocultural issues" [39], as depicted in the video clips. Thus, the well-planned tasks by the teachers play an important role in enabling learners to engage in the productive intercultural learning process and develop critical thinking towards the intercultural issues represented in the clips. Since the tasks are intended to facilitate intercultural learning, they generally strive to create learning activities where learners are able to identify and describe the cultural values embedded in the clips, critically analyse the various socio-cultural realities and phenomena through small group talk, and evaluate and reflect on them in class discussions. 
Video clip-assisted intercultural learning tasks can be applied across a variety of units, including Public speaking, basic English skills, and cross-culture understanding, as well as general or English for specific purposes in English-major and non-English-major departments. EFL teachers may use video-clips as the main learning materials in a full-time teaching hour or utilise them as supplementary learning aids used for activating students' background knowledge in a pre-activity or post-activity to aid retention. The following section details how one teacher uses video clips to improve students' CIA in Public Speaking.

\section{Before-teaching}

EFL teachers necessarily consider some preparational activities. First, they need to revisit their syllabus documents by including intercultural components as the learning objectives. Generally, Public Speaking (PS) syllabus for undergraduates provide students with basic theories, principles and practical experiences of public speaking. The unit mainly aims to assist students to plan and prepare a variety of speeches (informative, persuasive, demonstrative, and other special occasions), evaluate speeches based on specific criteria of verbal and non-verbal behaviour, and make use of presentation aids to enhance their speeches. Less attention has been given to how students should adapt their speeches to diverse target audiences. Thus, including this objective in PS aims to help students demonstrate awareness of and sensitivity to culturally diverse audiences, more effectively convey ideas in various cultural contexts, thereby preventing them from unnecessary miscommunications [40].

EFL teachers can go online to browse video-clips containing culturally appropriate content that align with the learning outcomes. They can select clips or segmental scenes that represent global or socio-cultural issues related to PS topics, for example about ethnocentrism, stereotyping, judgmental ways of thinking, verbal and nonverbal differences across cultures, religious practices and other related issues. Some topics may contain sensitive or taboo issues, for example, religion, terrorism, and racism; thus, teachers should be aware of and select clips carefully. EFL teachers may anticipate the level of risk by "sequencing learning activities in a way that moves from low- to high-risk disclosure, concrete to abstract concepts, personal to institutional examples, structured to unstructured activities and to sequence topics from low emotional intensity to higher emotional intensity" [9]. They need to guide students to approach and understand such issues from multiple perspectives, know what the sources of controversy are, know how to negotiate and compromise with their peer groups to seek alternative solutions and be able to convey ideas in nonjudgmental ways using culturally acceptable and linguistically appropriate language.

EFL teachers also need to spend considerable time preparing a mini-lecture highlighting the importance of intercultural values and intercultural communication competence. This helps equip them with foundational knowledge and awareness of interculturality through analysing the video contents using discourse theory as informed by Schirato [41]. The following questions may serve as guidelines:

1. Who is involved in the clip (role/social status)?

2. What happens?

3. Why does it happen?

4. What discourses are involved?

5. How are the values or issues negotiated?

6. What is the nature of the clip?

\section{Whilst-teaching}

The use of video clip-assisted intercultural tasks follows several procedures such as input, noticing, reflection, and verbal output $[34,42]$. The input stage provides students with authentic exposure to language and cultural knowledge in a variety of contexts by watching video-clip(s). Before playing the clip, EFL teachers need to group students heterogeneously into four or five, and then provide clear instructions on what they need to look for when watching the clip. To assist them to grasp the message or moral values, EFL teachers may give leading questions related to the main points being discussed. This helps activate students' prior knowledge and awareness of related issues and motivate their learning. While watching the clip, students should make notes on important socio-cultural realities depicted in it. These efforts aim to ensure students can understand the clip, and progress beyond their current understanding, as suggested by Krashen's input theory [43].

In the noticing stage, each group member is asked to share their observed unique cultural elements, and sociocultural similarities and differences within the group. Comparing and contrasting ideas encourages 
students to attend to uncertain features of input and notice gaps between one's own and others' beliefs [44]. In so doing, learners practice their ability to identify and interpret socio-cultural values depicted from learning materials (video-clips) [15].

Groups are then asked to reflect on what they have noticed with regard to the guidance questions. EFL teachers can encourage them to discuss what they have understood, negotiate, and exchange perspectives with other members of the group. Developing students' awareness of and acceptance on different perspectives helps shape attitudes and skills of intercultural communication. Long's interaction hypothesis [45] underlies this activity, particularly when group members work together to reflect on what they notice. This stage fosters students' ability to critically analyse the events or documents depicted in the clip in accordance with explicit perspectives and criteria.

The last stage is a verbal output process. EFL teachers can engage students in in-class discussion by employing various activities such as pair talk, group discussion, individual or group presentation, or debates. These activities are conducted to encourage students to produce verbal output [46]. For instance, teachers may voluntarily invite group member(s) to present their ideas and ask the class to respond. Through this inclass discussion and teachers' scaffolding, students are guided and encouraged to shape their views about socio-cultural issues represented in the clip in critical and non-judgemental ways [15]. Additionally, EFL teachers can extent the activity with an observational home assignment. For instance, students can choose to take out one of the intercultural encounters discussed in class, observe an everyday intercultural communication scenario or search for a short and interesting intercultural communication clip online via YouTube. Students are assigned to write a short reflection paper and share the result in the following meeting.

\section{After-teaching}

Eventually, EFL teachers are advised to reflect on the intercultural teaching. They can involve students in a Q\&A session to elicit their responses towards the intercultural learning process in the classroom and perceived development of intercultural awareness. Student feedback on teaching may be conducted anonymously to encourage students to provide additional information about their learning experience. This enables EFL teachers to reflect on the teaching effectiveness, including issues that need to be addressed in the future.

\section{Conclusion}

This paper conceptually discusses how the EFL teachers' CIA is developed in intercultural education and proposes strategies to develop EFL teachers' CIA in the Indonesian higher education context. Promoting intercultural education through video clips-assisted intercultural learning tasks has several possible impacts. EFL teachers benefit from raising their critical intercultural awareness (CIA) allowing themselves to broaden knowledge of interculturality and engage more in global communication and partnership. The ongoing formation of EFL teachers' CIA will likely improve their pedagogical skills to design interculturally based syllabi and deliver interculturally oriented classroom instructions to achieve the goal intercultural education. The classroom-based research, for example, is meaningful for EFL teachers to investigate the use of digital technologies or social media in various teaching spaces. Considering the significance of teacher CIA in the dynamic ELT, we call for institutional support for further EFL teacher professional development of their intercultural communication competence necessary for the future.

\section{References}

[1] W. Baker, "Intercultural awareness: modelling an understanding of cultures in intercultural communication through English as a lingua franca," Language and Intercultural Communication, vol. 11, no. 3, pp. 197-214, 2011.

[2] A. Mirzaei and F. Forouzandeh, "Relationship between intercultural communicative competence and L2-learning motivation of Iranian EFL learners," Journal of Intercultural Communication Research, vol. 42, no. 3, pp. 300-318, 2013.

[3] K. Piątkowska, "From cultural knowledge to intercultural communicative competence: changing perspectives on the role of culture in foreign language teaching," Intercultural Education, vol. 26, no. 5, pp. 397-408, 2015.

[4] M. Byram, A. Nichols, and D. Stevens, Developing intercultural competence in practice. Clevedon: Multilingual Matters, 2001. 
[5] T. J. Young and I. Sachdev, "Intercultural communicative competence: exploring English language teachers' beliefs and practices," Language Awareness, vol. 20, no. 2, pp. 81-98, 2011.

[6] C. L. McCalman, "International instructor preparing teachers for multicultural classrooms in the United States: teaching intercultural communication competence online," New Directions for Teaching and Learning, vol. 2014, no. 138, pp. 73-81, 2014.

[7] I. Gandana and G. Parr, "Professional identity, curriculum and teaching intercultural communication: an Indonesian case study," Language, Culture and Curriculum, vol. 26, no. 3, pp. 229-246, 2013.

[8] R. Wahyudi, "Intercultural languages education and its complex insights: the case of Indonesian Islamic higher education," Theory and Practice in Language Studies, vol. 2, no. 9, pp. 1783-1791, 2012.

[9] N. Dimitrov and A. Haque, "Intercultural teaching competence: a multi-disciplinary model for instructor reflection," Intercultural Education, vol. 27, no. 5, pp. 437-456, 2016.

[10] Q. Vo, "Rethinking intercultural communication competence in English language teaching: a gap between lecturers' perspectives and practices in a Southeast Asian tertiary context," $i$-Manager's Journal on English Language Teaching, vol. 7, no. 1, pp. 20-29, 2017.

[11] P. Yang, "Developing TESOL teacher intercultural identity: an intercultural communication competence approach," TESOL Journal, vol. 9, no. 3, pp. 525-541, 2018.

[12] J. G. DeJaeghere and Y. Cao, "Developing U.S. teachers' intercultural competence: does professional development matter? ," International Journal of Intercultural Relations, vol. 33, no. 5, pp. 437-447, 2009.

[13] D. E. Murray, What English language teachers need to know (vol. I): understanding learning. New York: Routledge, 2011.

[14] D. H. Hymes, "On communicative competence," in Sociolinguistics: selected readings, J. B. Pride and J. Holmes, Eds. Harmondsworth: Penguin, 1972, pp. 269-293.

[15] M. Byram, Teaching and assessing intercultural communicative competence. Clevedon: Multilingual Matters, 1997.

[16] R. L. Wiseman, "Intercultural communication competence," in Cross-cultural and intercultural communication W. B. Gudykunst, Ed. Thousand Oaks, CA: Sage, 2003, pp. 191-208.

[17] M. A. K. Halliday, Language as social semiotic: the social interpretation of language and meaning. London: Edward Arnold, 1979.

[18] C. Leung, "Convivial communication: recontextualizing communicative competence," International Journal of Applied Linguistics, vol. 15, no. 2, pp. 119-144, 2005.

[19] N. Galloway, Global Englishes and change in English language teaching: attitudes and impact. New York: Routledge, 2017.

[20] J. Liu and F. Fang, "Perceptions, awareness and perceived effects of home culture on intercultural communication: perspectives of university students in China," System, vol. 67, pp. 25-37, 2017.

[21] L. J. Choi, "Revisiting the issue of native speakerism: 'I don't want to speak like a native speaker of English'," Language and Education, vol. 30, no. 1, pp. 72-85, 2016.

[22] E. Ramirez, "Intercultural communicative language teaching (iCLT): a selection of practical points of departure," The New Zealand Language Teacher, vol. 44, pp. 18-30, 2018.

[23] M. Celce-Murcia, Z. Dornyei, and S. Thurrell, "Communicative competence: a pedagogically motivated model with content specifications," Issues in Applied Linguistics, vol. 6, no. 2, pp. 5-35, 1995.

[24] T. Q. Tran and T. M. Duong, "The effectiveness of the intercultural language communicative teaching model for EFL learners.," Asian-Pacific Journal of Second and Foreign Language Education, vol. 3, no. 6, pp. 2-17, 2018.

[25] W. Baker, "Research into practice: cultural and intercultural awareness," Language Teaching, vol. 48 no. 1, pp. 130-141, 2015.

[26] Ministry of Research Technology and Higher Education, National standard of higher education no 44/2015. Jakarta, Indonesia, 2015.

[27] G. Gay, Culturally responsive teaching: theory, research, and practice. New York: Columbia, 2010.

[28] L. Laroche, Managing cultural diversity in technical professions. New York: Butterworth-Heinemann, 2003.

[29] R. Berk, "Multimedia teaching with video clips: TV, movies, YouTube, and mtvU in the college classroom," International Journal of Technology in Teaching and Learning, vol. 5, no. 1, pp. 1-21, 2009. 
[30] C. Herron, B. Dubreil, C. Corrie, and S. P. Cole, "A classroom investigation: can video improve intermediate-level French language students' ability to learn about a foreign culture?," Modern Language Journal, vol. 86, no. 1, pp. 36-53, 2002.

[31] C. Herron, S. P. Cole, C. Corrie, and S. Dubreil, "The effectiveness of a video-based curriculum in teaching culture," Modern Language Journal, vol. 83, no. 4, pp. 518-533, 1999.

[32] E. Polisca, "Language learning and the raising of cultural awareness through internet telephony: a case study," Language Learning Journal, vol. 39, no. 3, pp. 329-343, 2011.

[33] A. Jacobsson, "Intercultural film: fiction film as audio-visual documents of interculturality," Journal of Intercultural Studies, vol. 38, no. 1, pp. 54-69, 2017.

[34] T.-C. Chao, "A diary study of university EFL learners' intercultural learning through foreign films," Language, Culture and Curriculum, vol. 26, no. 3, pp. 247-265, 2013.

[35] L. H. Yang and M. Fleming, "How Chinese college students make sense of foreign films and TV series: implications for the development of intercultural communicative competence in ELT," The Language Learning Journal, vol. 41, no. 3, pp. 297-310, 2013.

[36] C. Borghetti and J. Lertola, "Interlingual subtitling for intercultural language education: a case study," Language and Intercultural Communication, vol. 14, no. 4, pp. 423-440, 2014.

[37] J. Watkins and M. Wilkins, "Using YouTube in the EFL classroom," Language Education in Asia, vol. 2, no. 1, pp. 113-119, 2011.

[38] B. Crook, "Teaching intercultural communication with "an idiot abroad"," Communication Teacher, vol. 28, no. 1, pp. 9-13, 2013.

[39] R. Kusumaningputri and H. P. Widodo, "Promoting Indonesian university students' critical intercultural awareness in tertiary EAL classrooms: the use of digital photograph-mediated intercultural tasks," System, vol. 72, pp. 49-61, 2017.

[40] J. Xue, "Cultivating intercultural communication competence through culture teaching.," Theory and Practice in Language Studies, vol. 4, no. 7, pp. 1492-1498, 2014.

[41] T. Schirato, Communication and culture: an introduction. London: Sage, 2000.

[42] A. Liddicoat, J. Lo Bianco, and C. Crozet, Striving for the third place: intercultural competence through language education. Melbourne: Language Australia, 1999.

[43] S. Krashen, The input hypothesis. New York: Longman, 1985.

[44] R. Schmidt, "Attention," in Cognition and second language instruction, P. Robinson, Ed. Cambridge: Cambridge University Press, 2001, pp. 3-32.

[45] M. H. Long, "The role of the linguistic environment in second language acquisition," in Handbook of second language acquisition, W. C. Ritchie and T. K. Bhatia, Eds. New York: Academic Press, 1996, pp. 413-468.

[46] M. Swain, "The output hypothesis and beyond: mediating acquisition through collaborative dialogue," in Sociocultural theory and second language learning, J. P. Lantolf, Ed. Oxford: Oxford University Press, 2000, pp. 97-114.

\section{Biodata}

[1] Andi Susilo is a second-year PhD student supervised by Dr. Ping Yang and A/P Ruying Qi in the School of Humanities and Communication Arts at Western Sydney University. He has been teaching English as a foreign language at an Indonesian university for a decade and has been actively involved in several teacher professional development activities. His research interests include language teaching methodology, language curriculum development, and intercultural communication.

[2] Dr. Ping Yang is a Senior Lecturer in Linguistics and an Academic Course Advisor for Master of Arts in teaching English to speakers of other languages (TESOL) in the School of Humanities and Communication Arts at Western Sydney University. Dr. Yang has published and supervised $\mathrm{PhD}$ students in research areas such as intercultural communication, nonverbal communication, EnglishChinese translation, and teacher training in TESOL.

[3] Dr. Ruying Qi is Associate Professor, PhD Supervisor, Head of the China Liaison Unit, Director of Bilingualism Research Lab @WSU-JNU in the School of Humanities and Communication Arts, and an adjunct member of ARC Centre of Excellence for the Dynamics of Language. 